\title{
Desde la sacristía del Alax Pacha. «Calvarios de Poder» en el Altiplano aymara paceño (Bolivia)
}

\author{
Gerardo Fernández JuÁREZ \\ Universidad de Castilla-La Mancha \\ gerardo.fjuarez@uclm.es
}

Recibido: 23 de abril de 2015

Aceptado: 20 de noviembre de 2015

\section{RESUMEN}

El dominio ceremonial aymara emplea habitualmente en sus prácticas rituales objetos, oraciones y símbolos procedentes del catolicismo popular, destacando los abalorios específicos que forman parte de la parafernalia de los curas. Indudablemente la cruz y los crucifijos adquieren especial importancia en este sentido, siendo empleados por los especialistas en ritual aymaras, yatiris, del sector suburbano de Faro Murillo en plena barriada de Villas Dolores, en El Alto de La Paz. El artículo analiza las características de estos crucifijos ceremoniales, denominados «calvarios» por sus propietarios, y su vinculación con el rayo, uno de los principales referentes del poder ceremonial de los especialistas en ritual del Altiplano aymara

Palabras clave: Aymara, yatiri, calvario, crucifijo.

\section{From the Sacristy of the Alax Pacha. «Calvarios of Power» in the Aymara Highlands of La Paz (Bolivia)}

\begin{abstract}
Aymara ceremonial domain commonly used objects in their ritual practices, prayers and symbols from the popular Catholicism, highlighting specific beads that are part of the paraphernalia of priests. Undoubtedly the cross and crucifixes are especially important in this regard, being used by Aymara ritual specialists, yatiris, of suburban area of Faro Murillo in the neighborhood of Dolores Villas, in El Alto of La Paz (Bolivia). This paper analyzes the characteristics of these ceremonial crucifixes, called «calvarios» (calvaries) by its owners, and its relationship with rayo (lighting), one of the main references to the ceremonial ritual specialists of Aymara highlands.
\end{abstract}

Key Words: Aymara, yatiri, calvario (calvary), crucifix.

Sumario: 1. Introducción. 2. Iglesia y poder ceremonial: cruces y crucifijos andinos. 3. El Alto y el Sindicato de yatiris de Faro Murillo. 4. Yatiris y «calvarios». 5. Conclusiones. 6. Referencias bibliográficas.

\section{Introducción}

Las representaciones andinas sobre el «infierno», asociado a los términos uqhu pacha o manqhapacha, «mundo de abajo y de adentro» en aymara, adolecen de una relativa abundancia de relatos etnográficos que abarcan no sólo los de corte historiográfico y artístico, sino también los de índole antropológica y etnográfica, salpicados en ocasiones por la polémica relativa a la figura del diablo, supay (Absi 2005; Cereceda 2006, 2011; Estenssoro 2003; Gisbert 2011; Taylor 1980). El proceso de diabolización de los rituales amerindios es bien conocido en el amplio marco colonial y su expresión genérica más concreta a través de la extirpación de las idolatrías en el siglo XVII (Cervantes 1996; Fernández 2012; Redden 2008). No pasa lo mismo con respecto al dominio antitético del infierno, el «mundo de arriba», cielo o «gloria», tradicionalmente incorporado en el término alaxpacha. Obviamente, tanto el concepto 
alaxpacha como el concepto manqhapacha, sólo pueden identificarse con el «cielo» o el «infierno» católicos desde una perspectiva reduccionista incompleta o inadecuada. Pese a todo parece que hoy etnográficamente sabemos más y mejor sobre «el mundo de abajo» que sobre «el mundo de arriba», quizá al expresar los especialistas y académicos una mayor sagacidad analítica en relación con las categorías andinas del infierno y el diablo frente al catolicismo, mientras que las reflexiones sobre «el cielo» y sus categorías indígenas parecieran haberse impregnado automáticamente de sus contrapartes del catolicismo, mermando interés o atractivo para la indagación antropológica $^{1}$. La pesquisa antropológica sobre los motivos del cielo o «la gloria», término más frecuentemente utilizado por los aymaras con referencia al cielo, resultan tan atractivos y sugerentes en el análisis como puedan ser los específicos sobre el infierno, por todos los rasgos peculiares que incorporan en sus categorías andinas de expresión ${ }^{2}$.

La hibridación de categorías de contenido ritual que los diversos procesos de mestizaje han propiciado en el ámbito complejo de las sociedades andinas contemporáneas, es hoy evidente si nos circunscribimos de forma específica a la presencia de motivos propios del catolicismo y su campo semántico adscrito, en el caso de los rituales aymaras y quechuas contemporáneos.

A lo largo de estas páginas voy a tratar uno de estos rasgos, un elemento bien delimitado, mensurable, como son los «calvarios» de poder que exhiben en sus actuaciones ceremoniales los yatiris aymaras ${ }^{3}$, especialmente en el ámbito del Santuario de Copacabana, en los sectores suburbanos de la ciudad de La Paz y en acontecimientos masivos, como la Fiesta de las Alasitas de La Paz, o la Celebración de la Virgen de Urkupiña en el Santuario cochabambino de Quillacollo. Un signo católico de extrema universalidad como es la cruz, o su materialización portátil como son los crucifijos, adquiere particulares tintes y expresiones sofisticadas en el ámbito ceremonial aymara que nada tienen que ver con el modelo original del que aparentemente surge. Vayamos por partes.

\section{Iglesia y poder ceremonial: cruces y crucifijos andinos}

El término «calvario», en castellano, alude desde la perspectiva aymara a los lugares en los que ha caído un rayo, contaminándole de su poder ceremonial como acreditan los altares que se alzan en las cumbres y laderas de los cerros para testimoniar este hecho. Estos «calvarios» salpican el paisaje del altiplano lacustre del Titicaca, resultando frecuentes en las comunidades aymaras aledañas ejemplificando, como

\footnotetext{
1 Expertos en iconografía e historia como Gisbert (1980) han dedicado series completas al estudio de los programas iconográficos del catolicismo en los Andes. En este sentido merece la pena destacar la reciente obra de Cervantes y Redden (2013). Para un análisis de la Historia del Cielo, es necesario consultar la obra de Mc Dannell y Lang (2001).

2 Recordemos en este sentido los sinsabores en la prédica católica del padre Monast (1972) y las respuestas «heterodoxas» de sus feligreses aymaras sobre los motivos del catolicismo.

3 Yatiri: Sabio, «el que sabe». Especialista ritual aymara, diestro en los augurios mediante la consulta a las hojas de coca y en la elaboración de ofrendas rituales complejas, denominadas mesas, waxt'a.
} 
escenario sagrado, toda suerte de rituales relacionados con la vida en comunidad, la salud y la enfermedad, o la producción agrícola y ganadera (Fernández y Albó 2008).

No son estos «calvarios» los que ahora me preocupan, aunque es posible -como veremos- que tengan relación con ellos. Me voy a centrar en los «calvarios» o crucifijos de poder que emplean los yatiris de las áreas suburbanas de La Paz en sus actuaciones ceremoniales.

En primer lugar habría que llamar la atención sobre la relativa abundancia de términos en castellano en los rituales aymaras, como ha destacado Albó (1997) y muy especialmente procedentes del ámbito especializado del catolicismo. El concepto «calvario» asociado a la idea de lugar sagrado y altar, se refiere originalmente al «monte Calvario» donde se produjo la muerte de Cristo por crucifixión. La idea de «lugar sagrado» y el valor de la «cruz» como símbolo de poder me parecen significativos para lo que viene luego, sin desmerecer el hecho de la muerte de Cristo que en diferentes tradiciones populares, tanto amerindias como peninsulares, justifica todo tipo de desmanes, como sucedía tiempo atrás la noche del jueves al viernes santo en el ciclo de Semana Santa (Foster 1962).

No podemos obviar el impacto que los símbolos de la Iglesia Católica han ejercido en el dominio de los rituales andinos con el paso del tiempo. Son múltiples los ejemplos que podemos encontrar en la etnografía reciente desde el propio valor ceremonial otorgado al edificio de la iglesia ${ }^{4}$ y su torre, denominada turimallku, vinculada con los propios achachilas (Berg 1989); los discursos andinos construidos en torno a los motivos decorativos de las iglesias y sus programas iconográficos ${ }^{5}$; la inclusión de variantes andinas sobre las biografías de santos, santas, vírgenes y cristos, así como su presencia protagonista en rituales de sacrificio como las mesas y waxt $^{\prime} a s^{6}$; santidades heterodoxas con programas iconográficos procedentes de los motivos del catolicismo, como el caso del Niño Compadrito del Cuzco y otros santos y santas diríamos considerados por «aclamación popular» (Fernández 1998a); la presencia de

4 Este rasgo expresa la necesidad de disfrutar de los bienes sagrados del edificio eclesiástico, no sólo por parte de los feligreses andinos sino de de sus creaciones culturales y objetos de culto, caso de la bendición y aspersión de agua bendita que reciben los cráneos humanos el día de las ñatitas en la ciudad de La Paz (Fernández 2010).

5 Por ejemplo, el programa iconográfico presente en la iglesia de San Pedro de Andahualillas en la provincia Quispichachis del Departamento del Cuzco (Perú), conocido como «los dos caminos», o «el camino del cielo y el camino del infierno» (Gisbert 2011), modelo sugestivo presente igualmente en el capítulo de iniciación de yatiris y ch'amakanis de la orilla boliviana del lago Titicaca (Fernández 2004) y presente igualmente entre los grupos fundamentalistas evangélicos en La Paz (Ströbele-Gregor 1989). No olvidemos el impacto popular que en todo el territorio del catolicismo, tanto en América como en Europa y muy especialmente en la Península Ibérica, tuvieron los motivos expuestos en «retablos», «cúpulas», «frescos» y «pinturas» que, con pretensiones didácticas en la evangelización católica, dieron lugar a la expresión de figuras y formas heterodoxas, como en el caso de la figura de la Trinidad.

6 En el siglo XVII, un anciano de la localidad de Acas en Perú se quejaba de las «huacas de los españoles» con especial acritud por un razonamiento inapelable: «los camaquenes de los españoles que son los santos que están en las yglesias eran unos palos pintados y dorados, mudos que no ablan ni daban respuesta a lo que les preguntaban, pero que los Malqui y Camaquenes de los indios ablaban y daban respuesta de lo que preguntaban quando recibían sacrificios» (Rostworowski 1986: 11). El dato del anciano de Acas refleja la incomunicación inicial entre los protagonistas del santoral católico, que ni hablaban, ni recibían sacrificios de comida ritual, y los indígenas, imposibilitando la relación con sus nuevos feligreses. Este aspecto ha sido subsanado por los siglos y en la actualidad los seres del alaxpacha hablan a través de los especialistas rituales andinos y comen gustosos las ofrendas que les destinan; es el caso de la conocida como janq'u misa, «mesa blanca». 
personajes del santoral católico en las rogativas y letanías de los rituales andinos; la adscripción del latín como lenguaje ceremonial, al menos en parte, así como la presencia de términos en castellano de la liturgia católica incluidos en los ceremoniales andinos; la inclusión de objetos, actuaciones y rezos propios de la actuación del cura o vinculados a la liturgia cristiana, como las velas, el incienso, el vino, las campanas, la imposición de manos o los himnos religiosos, q'uchus (Albó 2005); la propia escenografía simbólica de la «última cena» como banquete ceremonial y altar, mesa, «mesada ${ }^{7}$; o las descripciones hechas sobre $\langle\text { la gloria }\rangle^{8}$ y sus personajes centrales.

Toda esta serie de motivos y muchos otros resultan de los modelos exitosos de hibridación simbólica y de apropiación por parte del campo de expresión ritual de los actores sociales aymaras y andinos, frente a las expresiones ceremoniales católicas. $\mathrm{Al}$ contrario, la apropiación de los motivos andinos por parte de los oficiales del catolicismo (estolas coloridas de tela de awayo, quema de incienso, ch'allas o libaciones públicas) no siempre han contado con el beneplácito de los asistentes a la eucaristía ${ }^{9}$.

Con respecto al motivo de la cruz, forma parte de la cosmogonía andina a través de la principal constelación que domina los cielos australes como es la Cruz del Sur, y está presente en las crónicas de Indias sobre la evangelización temprana de los indios que algunos cronistas pretendieron demostrar en narraciones de corte mítico, como la relacionada con la presencia de la cruz en la localidad de Carabuco, cerca del lago Titicaca, llevada a ese lugar, según la tradición, ni más ni menos que por el propio San Bartolomé (Poma 1987 [1615]). El signo de la cruz tomó claro partido en el proceso de extirpación de idolatrías en los Andes, tratando la sustitución simbólica de los lugares de culto tradicionales por los asignados, a lo largo de los siglos XVI y XVII, al catolicismo (Arriaga 1968 [1621]). Es así que cruces vestidas, decoradas o desnudas, pero cubiertas con ofrendas, aparecen de forma generalizada por el espacio andino, conviviendo de una manera razonable con machulas, apus, achachilas y apachitas ${ }^{10}$. Cruces y santos resultan solidarios en la demarcación del espacio ceremonial andino incluyendo diferentes polisemias, no tan «católicas», sobre piedras, cerros y quebradas (González 1989).

7 El término «mesa», o «mesada», en alusión a la mesa altar o mesa de sacrificio, ha tenido éxito en la identificación de ofrendas complejas en los Andes del Sur y en los procedimientos rituales de intervención de corte chamánico con utilización del «sanpedro» (Trichocerus pachanoi) en el litoral del Norte peruano (Sharon 1980).

8 El término más empleado por los yatiris aymaras en referencia al alaxpacha es luriya del castellano «gloria». Esta «gloria» es el lugar donde se encuentran los santos, vírgenes y seres sagrados del catolicismo junto a otros personajes específicos de las creencias y los rituales andinos, como son los rayos, estrellas fugaces, antawayas, y demás fenómenos meteorológicos, lo que sin duda ofrece un cierto regusto peculiar a este «cielo andino», francamente heterodoxo.

9 El acercamiento, la proximidad utilizando elementos decorativos del contexto o rituales, no siempre han gozado de la aceptación de los devotos «¿por qué el padre hace como yatiri?»; mientras que el yatiri haga como «el padre», en algunos episodios, parece bien reconocido.

10 Todas ellas denominaciones específicas en quechua y aymara para los cerros, al igual que las «abras»o pasos de cordillera, generalmente coronados en el cambio de vertiente por una cruz que disimula todavía en la actualidad -no con mucho éxito- el sistemático culto de que son objeto por parte de los chóferes y viajeros, caso de las apachitas que rodean las quebradas en torno a la ciudad de La Paz y sus salidas hacia los Yungas, Larecaja, Rio Abajo y Oruro. 
Los crucifijos ceremoniales que vamos a ver están claramente inspirados en los empleados por los curas católicos en sus actuaciones litúrgicas y ceremoniales ${ }^{11}$. De hecho parecen «rosarios» aunque de un aspecto desproporcionadamente grande puesto que al tamaño de la cruz, aproximadamente de un par de cuartas, se añade la disposición de cuentas de colores que semejan las propias de los rosarios y otros aditamentos que veremos luego.

Los crucifijos a manera de grandes «rosarios» aparecen descritos en la obra de Guamán Poma en el siglo XVII, estableciendo un vínculo entre estos, los quipus, las oraciones católicas y la escritura o qillqa (Poma 1987 [1615]). El empleo de crucifijos como objetos ceremoniales andinos es habitual en el sindicato de Faro Murillo, en la barriada de Miraflores de El Alto de La Paz, e incluso los emplean los yatiris del «calvario» del Santuario de Copacabana, de donde dicen proceder, para «mirar la coca». También aparecen con frecuencia en ciertos entornos festivos masivos como la fiesta de las «alasitas» de La Paz o la festividad de Urqupiña en el Santuario de Quilacollo en Cochabamba ${ }^{12}$, como reflejaba al principio. Del mismo modo están incorporados los crucifijos como «objetos de poder» ceremonial entre los aditamentos rituales de autoridades comunales, caso de los propios mallkus de Jesús de Machaqa en la Provincia Ingavi del Departamento de La Paz (Ticona y Albó 1997). En algunos casos, estos emblemas o signos de autoridad en forma de cruz que portan las autoridades comunales adquieren la forma de «cruz escalonada» supuestamente derivada de los motivos tiahuanacotas y de la wiphala o bandera andina. En los socavones potosinos los crucifijos del exterior colocados en la entrada de la mina denominados tata q'axchus velan por la salvaguarda del interior de mina, evitando que el «Tío», el diablo, salga de sus dominios subterráneos y ocasione el caos en los poblados mineros (Absi 2005).

Los crucifijos que utilizan los yatiris paceños de áreas suburbanas, como el distrito de Faro Murillo, en El Alto de La Paz, proceden en su mayoría, como he comentado, del Santuario de Copacabana donde pueden adquirirse. La cuestión principal es que el crucifijo hay que «tunearlo» convenientemente ${ }^{13}$ para que muestre de forma no verbal, la capacidad ceremonial de quien lo porta en una propuesta sorprendente de biografía ceremonial que expone públicamente los saberes y poderes de su propietario.

Voy a presentar algunos ejemplos de estos «calvarios de poder» o «crucifijos rituales» característicos en los usos ceremoniales de estos yatiris alteños, pero primeramente debemos familiarizarnos, en parte, con su contexto social de actuación.

\footnotetext{
11 «Yo trabajo como el tata cura, pero sin el libro», me comentaba Modesto Capcha en su carpa de Faro Murillo.

12 Es significativa esta presencia mayoritaria de los crucifijos ceremoniales entre los yatiris de áreas suburbanas que lucen en las grandes festividades locales. En la fiesta de las alasitas, cada 24 de enero, los paceños adquieren miniaturas de toda clase que son bendecidas por los yatiris con el deseo manifiesto de que se conviertan en realidad. Es la festividad del Iqiqu, el diosecillo de la abundancia aymara que ha adquirido resabios mestizados (Fernández 1998b; Paredes 1982). Por su parte, los cochabambinos hacen otro tanto en el santuario de la Virgen de Urkupiña en el Calvario de Quillacollo, cada 16 de agosto, bendiciendo los yatiris las piedras extraídas de la «mina» o «cantera» del santuario (Salvador 2012)

13 En este sentido el tratamiento del crucifijo no es únicamente material sino que incorpora toda una serie de cuidados ceremoniales que pretenden habilitarlo para el ejercicio de sus funciones rituales.
} 


\section{El Alto y el Sindicato de yatiris de Faro Murillo}

El área periurbana de mayor crecimiento en los últimos años en Bolivia lo ha constituido El Alto de La Paz que, a principios del siglo XX, era apenas una pequeña venta desde la que se divisaba la hoyada paceña, y que en la actualidad se acerca al millón de personas, constituyendo unas de las principales ciudades de Bolivia. El porcentaje de emigrantes en El Alto supera el 60\%, y de ellos más del 75\% son de origen aymara, en concreto de las comunidades próximas al lago Titicaca; el resto lo constituyen empresas y sectores de población relocalizada como es el caso de los mineros de Potosí y Oruro (Sandóval y Sostres 1989; Unitas 1988). Conocida a finales de los años de 1980 y 1990 como «La ciudad del futuro», sus pobladores han mostrado un especial compromiso en mejorar sus infraestructuras de comunicación, alcantarillado, luz, servicios básicos, educación y salud, saliendo a la calle y bloqueando los caminos en los principales choques que se produjeron durante la legislatura de Gonzalo Sánchez de Lozada, que acabó con su huida del país y posterior refugio en los Estados Unidos. La ciudadanía alteña constituye un sector muy crítico con los ejecutivos bolivianos y sus compromisos electorales, incluso con el actual gobierno bajo la presidencia del aymara Evo Morales Aima.

El Alto adolece de problemas similares a los de los «pueblos nuevos» y «villas pobres», lamentablemente muy presentes en los principales núcleos urbanos en América Latina, en los que las condiciones de vida resultan mayoritariamente difíciles para la población ${ }^{14}$ más allá de las dificultades de acceso a los servicios básicos que son responsabilidad de la municipalidad, y donde la vida se realiza prácticamente en la calle. Es así que la población alteña sufre en especial además de los rasgos reconocidos de la llamada «cultura de la pobreza», violencia doméstica y machista, alcoholismo, drogadicción, paro juvenil, racismo, pandillaje, inseguridad ciudadana, abusos sexuales, etc., problemáticas que padece de manera especial la población emigrante de origen aymara (Cottle y Ruiz 1993).

La situación vivida de forma habitual por sus residentes explica el ámbito complejo de los rituales urbanos de índole doméstica, inspirados en los de tradición aymara y andina, pero adaptados a las características y peculiaridades de la ciudad. Es así que las llamadas «mesas de maldición»o ch'íyara misas adquieren un especial protagonismo en los mercados de remedios de Sagrado Corazón y Faro Murillo próximos a la Ceja de El Alto, certificando la amplitud de complejos conflictos sociales que, característicos del dominio alteño y urbano, son canalizados, al menos en parte, a través de su sacrificio ceremonial.

Así lo expresaba Modesto Capcha: «En la ciudad todo es pura ch'iyara misa; la mujer con otro anda, no hay pega, los rateros roban, así no más», circunstancia de marcado contraste con respecto a los conflictos presentes en las comunidades rurales, que son de otra índole y justifican el rechazo que produce la ch'iyara misa y su ofrecimiento casi clandestino.

14 El desconocimiento por parte de las elites paceñas de las vicisitudes por las que pasa la población alteña resulta sonrojante. Muchos de ellos no tienen mayor conocimiento o contacto que el que se produce a través del aeropuerto internacional de El Alto. Ni que decir tiene en relación con las propias poblaciones campesinas. 
En este entorno urbano problemático destaca la presencia de importantes concentraciones de «maestros ceremoniales», yatiris, en diferentes sectores de la ciudad, especialmente en los miradores y vertientes que desde la ciudad de El Alto contemplan la hoyada de La Paz y los nevados de la Cordillera Real ${ }^{15}$. Igualmente son importantes los mercados que venden los objetos ceremoniales para ser empleados en los sacrificios rituales que se realizan en las ciudades. Sin duda, los más importantes resultan el Mercado de las Brujas de La Paz y el Mercado del Sagrado Corazón en la Ceja de El Alto, en el principal nudo de comunicaciones entre La Paz, El Alto y las comunidades del altiplano paceño.

Los mercados urbanos de remedios caseros, herboristería tradicional y productos ceremoniales, jamphi qhatus, constituyen una mezcla en constante dinamismo de productos que generan no sólo la medicina popular y el ritualismo aymara o andino en general, sino el complejo entramado social y cultural de la ciudad, e incluso la globalización, propiciando la venta de perfumes, ungüentos y pócimas relacionados con la magia amorosa, talismanes y amuletos de toda índole, muy similares en mercados aparentemente alejados entre sí como el de La Paz o su similar de Lima.

En el sector de Faro Murillo de El Alto de La Paz, perteneciente a la barriada de Villa Dolores, se encuentran las pequeñas carpas o tiendas provisionales donde atienden los yatiris del sindicato de Faro Murillo, a lo largo de lo que era la línea férrea La Paz-Arica (Chile). Los yatiris agrupados en el sindicato pagan una pequeña cuota por el terreno que ocupan para no tener problemas con la policía ${ }^{16}$.

A finales de los años 80 del pasado siglo, conviví durante varios meses con varias familias de yatiris emparentadas entre sí: las familias de Gregorio Condori Tayakawa, su hermano Gabriel Mamani Tayakawa, su hijo Germán Mamani, y el compadre de Gregorio, Modesto Capcha. Durante varios meses residí de forma alternativa en las casas de Gregorio y Modesto, mientras asistía como ayudante a las sesiones de consulta a la hoja de coca, o a la realización de ofrendas rituales destinadas a los residentes de la barriada, en gran medida aymaras procedentes de su misma región de origen, la provincia Omasuyos, junto al lago Titicaca.

Gregorio Mamani Tayakawa es originario de la comunidad de Kajiyata junto al lago Titicaca (Provincia Omasuyos del Departamento de La Paz), y es uno de los yatiris pioneros en la zona de Faro Murillo, desempeñándose como «maestro ceremonial» en la ciudad desde los años de 1970. Ha enseñado a su hijo menor, Germán, los secretos del oficio de yatiri, y su hija Victoria posee un puesto de remedios ceremoniales al lado de la casa.

La totalidad de los actuales yatiris formados por Gregorio que pertenecen a su saga familiar, han efectuado el proceso migratorio a la ciudad en busca de mejores opciones de vida para ellos y sus familias. En un contexto económico como el que se

15 Javier Medina me comentó que estos lugares o miradores ceremoniales donde se concentran los maestros ceremoniales andinos, coincidían con posibles huacas o adoratorios ceremoniales de origen precolombino que circunvalan la ciudad.

16 Los yatiris alteños de Faro Murillo guardan en su mayor parte poderosos vínculos con su comunidad de origen, desempeñándose como ganaderos y agricultores cuando la situación lo precisa. No suelen descuidar tampoco sus responsabilidades cuando les corresponde ejercer como autoridades comunitarias, jilaqatas o mallkus. 
produce en las comunidades lacustres y en el que destaca el minifundio de productores campesinos que cultivan variedades de tubérculos de altura (papa, oca, isañu), gramíneas como la quinoa, variedades de cebada, algunos espacios de trigo y maíz enano (en los sectores más protegidos de la helada), que compaginan con reducidas recuas ganaderas de índole doméstico consistentes en pequeñas cabañas de ovejas, podemos imaginar la dificultad que el cambio de vida supone (Albó, Greaves y Sandoval 1981). El ganado vacuno se emplea en el trabajo del campo, especialmente la yunta de bueyes para la siembra. Pocas familias se dedican a explotación del cerdo (chancho), y sólo algunas tienen gallinas ponedoras, así como wank'us o cuys. Las zonas comunes de pasto, en las laderas de los cerros, son muy reducidas y poco abundantes, circunstancia por la que, según dicen los comuneros, no pueden sostener la crianza de llamas. Las comunidades aledañas del lago Titicaca combinan su actividad agrícola con la pesca del pejerrey, el karache y la elaboración de ispis (peces deshidratados) y $\operatorname{ch}^{\prime} u \tilde{n} u^{17}$.

El pueblo de Achacachi, de habla mayoritariamente aymara situado a un centenar de kilómetros de la ciudad de La Paz, constituye la capital de la provincia Omasuyo (Molina y Albó 2006). La localidad cuenta con su municipalidad, iglesia, cementerio, hospital, cuartel, casa de gobierno, y alojamientos hoteleros que viven de la situación estratégica de la población como lugar de tránsito; son abundantes sus pensiones para comer que aprovechan los viajeros y sus talleres mecánicos, y el surtidor de gasolina. Hace unos años era conocida su «tranca» militar o barrera, que suponía un primer control de población y mercancías procedentes del lago, zona alternativa empleada por los comerciantes peruanos en su desplazamiento de contrabando hacia La Paz.

Existen en el pueblo algunos gremios de bordadores y sindicatos de chóferes, maestros rurales y transportistas especialmente vigorosos en los tiempos de los bloqueos de caminos que acabaron con los gobiernos previos a la asunción al poder de Evo Morales. En estos bloqueos de caminos tuvieron una significación especial los campesinos productores de leche que venden a las cooperativas y que no pudieron aguantar los bloqueos instigados por «el mallku», Felipe Quispe, figura política destacada en la localidad en los años noventa del pasado siglo, que perdió buena parte de su fuerza y apoyos en el sector con el advenimiento de Evo Morales ${ }^{18}$. Achacachi,

17 La introducción de la trucha en el lago supuso poner en peligro serio de extinción a las especies autóctonas. Existen pequeñas explotaciones de truchas y piscifactorías que cuidan de los alevines de trucha para la explotación comercial. Los ispis y los pequeños quesos de leche de vaca son, junto a las papas del altiplano, muy codiciados por las comunidades vallunas, como las del Valle de Larecaja, estableciendo modalidades de trueque entre los pobladores de los diferentes nichos ecológicos, Los vallunos ofrecen cítricos, frutas y maíz a cambio de los productos del altiplano: papas, queso, ispi y ch'uñu o papa deshidratada.

18 La historia contemporánea de Achacachi es parte de la historia de la lucha campesina e indígena en Bolivia por adquirir derechos y reconocimiento frente a una oligarquía minoritaria excluyente (Albó 1979; Albó y Barnadas 1985). Este sentido de «coraje» de la localidad por la defensa de sus derechos le ha valido una simbología cruel por parte de las elites urbanas paceñas que se refieren a los achacacheños con el apelativo de «lazo seguro» por su supuesta violencia y radicalismo. Estos conceptos simbólicos que el imaginario mestizo y urbano ha configurado sobre los lugareños de Achacachi a través de sus miedos, ha encontrado justa respuesta en los propios lugareños que suelen referirse a si mismos como chachamarkatwa, «soy de los corajudos» en alusión al valor y virilidad demostrada por los achacacheños a lo largo de su historia. Durante los bloqueos de caminos y la violencia subsiguiente algunos de estos imaginarios sobre la supuesta violencia de los lugareños destacaba en los relatos de la prensa oficialista. Las élites criollas de La Paz refuerzan la idea de bestialismo y ferocidad de los lugareños achacándoles incluso tendencias caníbales. No es de extrañar que 
localidad que fue explotada por los hacendados en su historia republicana, ha recuperado recientemente por iniciativa de varias asociaciones aymaras locales la estructura de sus antiguas autoridades tradicionales, tata mallkus y mama t'allas, que son las que defienden de una forma singular el valor patrimonial inmaterial de los lugares ceremoniales de la comunidad ${ }^{19}$.

Pese a todo, la municipalidad de Achacachi ocupa el puesto 40 dentro de las localidades bolivianas de alta pobreza en el país, lo que permite hacernos una idea de las características de la vida en este sector del altiplano lacustre, y los motivos claros del proceso migratorio a la ciudad por parte de los yatiris de Faro Murillo (Albó 1995). De hecho, alguno de ellos, con apenas ciertos conocimientos recién aprendidos en la consulta de la hoja de coca, se lanzó a la aventura urbana con el apoyo de sus paisanos de Faro Murillo, a sabiendas de que algo de «plata» iba a conseguir, especialmente en las atenciones rituales del sector de las mujeres aymaras que ocupan el servicio doméstico en la ciudad de La Paz y que constituyen parte importante del mercado ceremonial alteño.

\section{Yatiris y «calvarios»}

Gregorio es uno de los yatiris de mayor prestigio y reconocimiento del sector de Faro Murillo. Presenta una clara discapacidad en forma de sistemática cojera que se produjo al accidentarse de pequeño; parece que saltó desde lo alto de un muro de adobe quebrándose la pierna; por esa razón, cuando camina, se apoya en unas muletas de forma permanente. Gregorio es $i s p a^{20}$; tenía una hermana gemela ya fallecida. De aquí le viene el poder para desempeñarse como «maestro ritual». Pero además «tiene rayo»; le cayó siendo muy niño ${ }^{21}$. Todos estos indicadores resultantes de su propia biografía forman parte del prestigio ceremonial de Gregorio Mamani como yatiri, al reunir en su persona las peculiaridades de los sabios que son tocados por el rayo ${ }^{22}$, proceden de un nacimiento múltiple y además poseen un cuerpo con una ostensible discapacidad, hechos que, por sí solos, resultarían suficientes para que una persona

en las crisis gubernamentales previas a la consecución del poder por parte de Evo Morales, se hablara de los «ponchos rojos» de Achacachi en alusión a los ponchos wayruru, típicos de la región del lago Titicaca, como supuesta guardia pretoriana del líder indígena capaz de asaltar la capital del gobierno e imponer violentamente sus convicciones.

19 En Jesus de Machaqa (Provincia Ingavi) se ha consolidado el sistema de autoridades comunitarias tradicionales con un gran respaldo social (Ticona y Albó 1997).

20 Los ispa, hermanos gemelos, se consideran «tocados por el rayo», pudiendo dedicarse al desempeño como «maestros» ceremoniales tras la iniciación correspondiente. En el dominio aymara, sin embargo, no se considera favorable el parto de gemelos, especialmente cuando los hermanos son de diferente sexo, ya que, se dice, han estado juntos como marido y mujer en el seno de la madre. No resulta extraño que se produzca la desatención de uno de ellos, generalmente de la niña, que termina falleciendo. «Yo Ispa, también, mi mamá dos ha nacido, uno, mi hermana ya hemos «morto» yo no más estoy vivo», comenta el propio Gregorio.

21 Así lo comenta Germán, su hijo: «Le ha caído [el rayo], con seis añitos había llegado pues rayos de noche, después se había matado [muerto], entonces ya se había «amilagrao», milagroso, había vuelto, así es». Germán describe el clásico motivo del regreso a la vida entre los yatiri golpeados por el rayo, y su retorno infundidos del poder ceremonial pertinente para aspirar a convertirse en yatiris.

22 En el período colonial los especialistas en ritual andino eran conocidos como «hijos del rayo» (Mariscotti 1978). 
pudiera iniciarse como «maestro ritual» según las creencias aymaras. Desde pequeño Gregorio Mamani comenzó a desempeñarse como «maestro» ceremonial; al parecer poseía una peculiar habilidad para aprender himnos religiosos y oraciones católicas, así como una gracia particular y destreza en la lectura de hojas de coca.

\section{Así nos cuenta su hijo Germán Mamani:}

«Desde chiquitito siempre ya ha trabajado desde 12 años ya estaba maestro, ya estaba Copacabana, Pachjiri, ya estaba todo pasaba calvarios ${ }^{23}$, hacía pedir de calvarios, orden, sacar orden ${ }^{24}$, orden de calvarios» ${ }^{25} \ldots$ «Así siempre ha nacido ${ }^{26}$, de chiquitito así sabía rezos todavía, lindos, desde pequeño '...nanakan awkixa alaxpachankiritawa ${ }^{27}{ }^{27}$ Todo sabe hacer! Desde pequeñito, nadie le ha enseñado pues. Mi papá está enseñando al Mariano, al Gabriel, le enseñó mi papáa ${ }^{28}$ 》.

Gregorio es casi monolingüe aymara, apenas habla castellano; es fiel devoto de la Virgen de Copacabana y gusta de desplazarse a los principales santuarios visitados por los yatiris del lago Titicaca, pero en especial al Calvario de Copacabana. Dice haber visitado el cerro Pachjiri, y Santiago de Guaqui:

«estamos viniendo al Copacabana, Copacabana y calvario Pachjiri también esto Guaqui, otro cerro, ahí no más yo anda, estoy yendo; después eso no más estoy alzando; después yo sabe bien. Todos los calvarios enseñan ${ }^{29}$. Después estoy aprendiendo, poquito, poquito después... ¡bien estoy! Suerte bien».

Gregorio Mamani posee un lugar de prestigio en el sindicato de los yatiris de Faro Murillo. Su prestigio y relevancia como «maestro» vienen acreditados por el crucifijo que emplea en las consultas de hoja de coca (Figuras 1 y 2). El crucifijo de Gregorio, al que denomina «calvario», constituye el emblema sensible de su poder ceremonial.

Según sus propias palabras, son seis los «calvarios» que su crucifijo muestra de forma superpuesta: 1) la cruz principal; 2) la propia figura del Cristo crucificado; 3) y

23 Una práctica habitual de los buenos yatiris consiste en visitar los espacios ceremoniales más relevantes del altiplano, es decir los altares o «calvarios» de mayor significación sagrada. Germán alude al calvario de Copacabana y al reconocido cerro Pachjiri, cuyos altares ceremoniales son visitados en el proceso de formación de los yatiris de la zona (Fernandez y Albó 2008).

24 Sacar orden: pedir permiso.

25 Indudablemente los yatiris que obtienen permiso para ejercer a una edad tan temprana son algo excepcional; no constituye el modelo habitual de iniciación. Esta circunstancia especialísima redunda en el prestigio del novel «maestro» y en su proyección personal.

26 Para Germán, las habilidades de su padre como yatiri responden a un don especial cuya explicación radica en su naturaleza ispa, gemelar.

27 Comienzo del Padre Nuestro en aymara.

$28 \mathrm{El}$ hecho de que fuera Gregorio el maestro formador de yatiris de esta zona de Faro Murillo puede justificar el parecido formal en la elaboración de las ofrendas rituales que algunos presentan, principalmente su hijo Germán Mamani y su compadre Modesto Capcha. El caso de Gabriel Mamani, su hermano, es diferente, aunque sigue también el modelo circular y el desarrollo levógiro de la ofrenda. Bien es cierto que cada uno de ellos realiza los rituales de manera singular, aportando alguna novedad personal de estilo. El aprendizaje «autónomo» «sin preguntar», resultado de la propia reflexión, vivencia e iniciación discreta, constituye uno de los rasgos que acreditan el prestigio de los yatiris más relevantes en el altiplano.

29 Gregorio es tajante en su afirmación: los lugares sagrados, los cerros y «calvarios» enseñan a los yatiris y potencian su eficacia ceremonial. Ya conocemos la costumbre de los yatiri de visitar esos lugares para acrecentar su poder y renovarlo. Los cerros achachilas son los responsables de la iniciación ceremonial de los yatiris mediante sueños. 


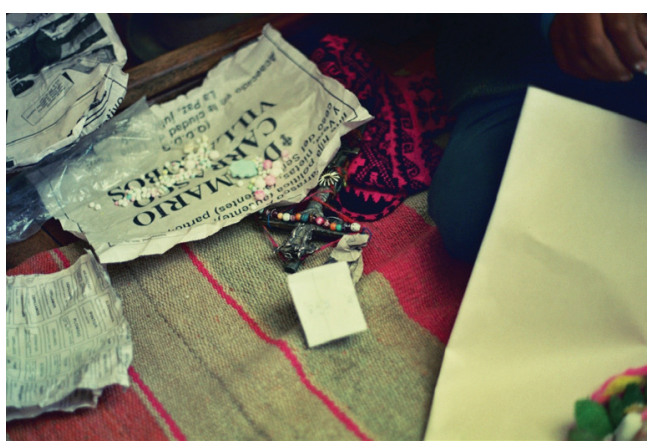

Figura 1: El «calvario» de Gregorio.

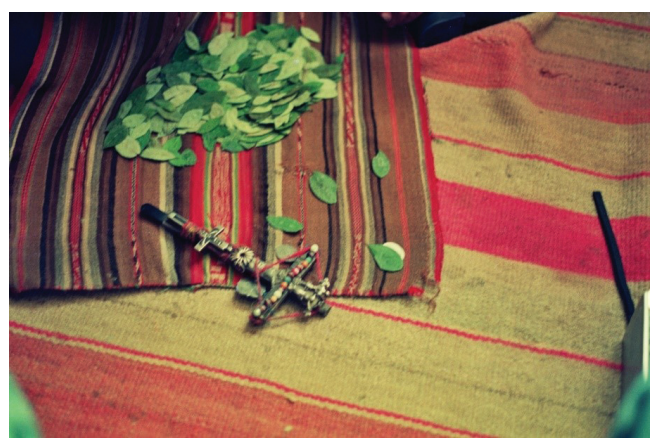

Figura 2: El «calvario» de Gregorio. Consultando a las hojas de coca.

4) los crucifijos más pequeños que están amarrados a derecha e izquierda de la cabeza del Cristo principal; 5) el crucifijo pequeño a los pies del Cristo principal; y 6) otra cruz de madera que por detrás ostenta amarrada a la cruz principal. Al igual que el sacerdote, Gregorio porta un crucifijo que no es «uno» sino «seis» para destacar su poder como maestro ceremonial. Cada elemento que integra su crucifijo o «calvario» justifica de forma sensible su calidad y poder. «Todo sé hacer». El «calvario» de Gregorio es el documento acreditativo de los saberes ceremoniales que posee, algo así como su bastón de mando y emblema de jerarquía entre los yatiri de Faro Murillo; es decir, la encarnación sensible del rayo y su poder en un objeto material concreto como la cruz que, a la manera de «capilla portátil», activa cuando lo necesita. Los «calvarios» presentes en su cruz otorgan a Gregorio poder y destreza en la consulta de la hoja de coca ${ }^{30}$; su crucifijo posee dos medallas que Gregorio identifica con las vírgenes de Copacabana y Urkupiña, a las que pide por sus pacientes acreditando su poder tanto sobre pachamama como sobre «gloria» ${ }^{31}$. A los pies del Cristo principal hay una figura que Gregorio identifica como «corona», elaborada con grapas en sentido contrario a las agujas del reloj; Gregorio dice que es para el «brujo», para devolver las «maldiciones» ${ }^{32}$. Finalmente el crucifijo posee 16 pequeñas cuentas de collar de varios colores dispuestas en línea recta sobre la cabeza del Cristo principal, recorriendo de forma longitudinal el brazo corto de la cruz, que Gregorio identifica con la llamada del «animo» ${ }^{33}$, es decir para recuperar las entidades anímicas que las personas pierden en determinadas circunstancias, y cuyo extravío puede provocar

30 «Calvario es, cuatro, aquí, cinco...seis los dos es amarrado. Eso significa los crucifijos para Inalmama, coca para leer coca, como calvario».

31 «Para negocio, para viaje, para estudio». Las medallas de Urkupiña y Copacabana son empleadas por Gregorio en las solicitudes que interesan en las mesas de pachamama y «gloria» de la ciudad.

32 «Corona, es para brujo estamos haciendo bien. Esa mesa negra, esta es», señalando la corona del crucifijo. La «corona» del crucifijo representa la «mesa negra» con su presencia de elementos espinosos y duros. La denominación «corona» en castellano, ¿aludirá a la corona de Cristo, la corona de la pasión, efectuada con espinos que son la materia prima de los hechizos y maleficios aymaras? Merece la pena considerar la relación existente de este motivo «corona» del crucifijo de Gregorio con el ideograma tatanchik propio de las qillqa y risalip'ichis o sistemas escriturarios no alfabéticos presentes en los Andes del Sur para el aprendizaje de oraciones católicas (Garcés y Sánchez 2014; Szeminski 2010).

33 «Para animu, para llamar animu; con eso vamos a llamar animu». 

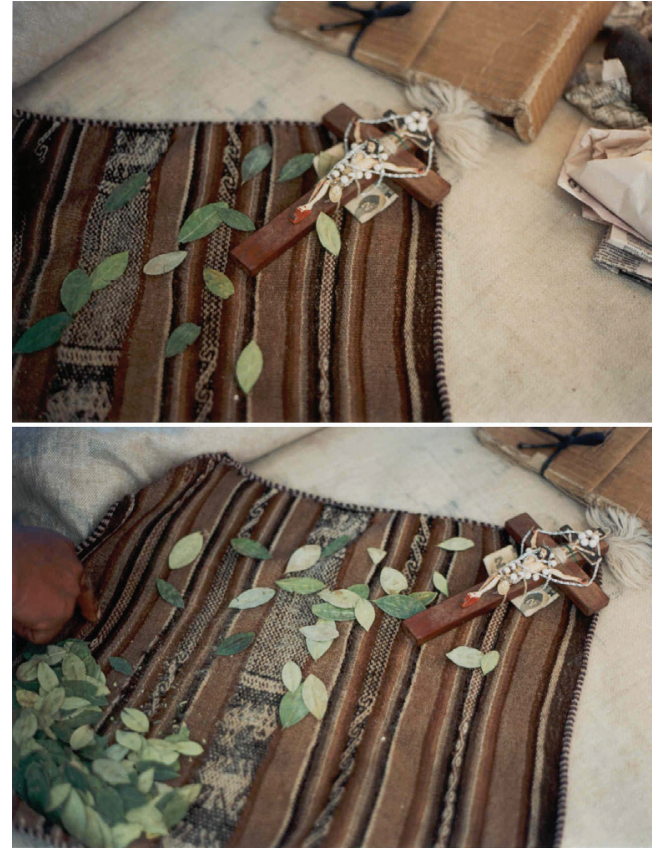

Figura 3: «Calvario» de Gabriel Mamani. Consultando a las hojas de coca.

graves enfermedades como el «susto», katjiyata, «agarrado».

El «calvario» de Gregorio exhibe públicamente las competencias ceremoniales de su propietario y su liderazgo ceremonial dentro del sindicato de yatiris de Faro Murillo. La complejidad y el sumatorio de motivos que están presentes en su «calvario» acreditan la competencia de Gregorio como hábil interlocutor entre los mundos de «arriba» (alaxpacha), este mundo (akapacha) y el mundo de abajo y de adentro (manqhapacha). Por otro lado, como sucede en el domino aymara y andino, sus competencias rituales no sólo se ajustan al dominio del bien, sino que muestra competencias para el rechazo de las maldiciones y maleficios, lo que supone otra forma efectiva de producirlos. Todo esto bajo la forma externa de un sumatorio de cristos crucificados, medallas y cuentas de colores que reflejan el dominio complejo y diverso de una cosmovisión aymara sobre la que Gregorio interviene, según las necesidades de su clientela.

Las diferencias del «calvario» de Gregorio con respecto a otros yatiris de su linaje presentes en Faro Murillo son muy significativas. Su hermano Gabriel Mamani presenta otro crucifijo complejo con la incorporación de un segundo «calvario» a la cabecera del Cristo central (Figura 3). Incluye la incorporación de medallas y posee cuentas de color blanco colocadas a manera de corona sobre el Cristo de la cabecera y otras pequeñas que envuelven en forma de cadena la figura del Cristo principal.

Por su parte, Modesto Capcha, compadre de Gregorio, posee un calvario «sencillo» ${ }^{34}$, sin apenas modificaciones personales, con una significativa seriación de cuentas dispuestas en una notable degradación cromática a lo largo de todo el crucifijo $^{35}$. Posee dos medallas de las vírgenes de Copacabana y Urkupiña adosadas a ambos lados del crucifijo (Figura 4)

\footnotetext{
34 Es el mismo caso de Germán Mamani, hijo de Gregorio que en aquellos años estaba iniciándose como yatiri y exhibía en sus actuaciones ceremoniales un crucifijo sencillo, sin añadido alguno, como correspondía a su categoría de entonces como yatiri principiante.

35 La degradación cromática es constitutiva de la calidad de las entidades anímicas (ajayu, kuraji y animu) que incorporan los jaqi, los seres humanos del altiplano en la zona del lago Titicaca (Fernández 1999). En este sentido, el concepto de ser humano incorporando la tríada completa de sus entidades anímicas guarda relación con el aspecto estilístico en degradación cromática, $k^{\prime} i s a$, de los awayu y textiles más significativos de la zona del lago Titicaca (Cereceda 1987). Recordemos cómo las cuentas vidriadas acreditan la capacidad y competencia del especialista para combatir la enfermedad del «susto», según hemos visto en el testimonio de Gregorio.
} 


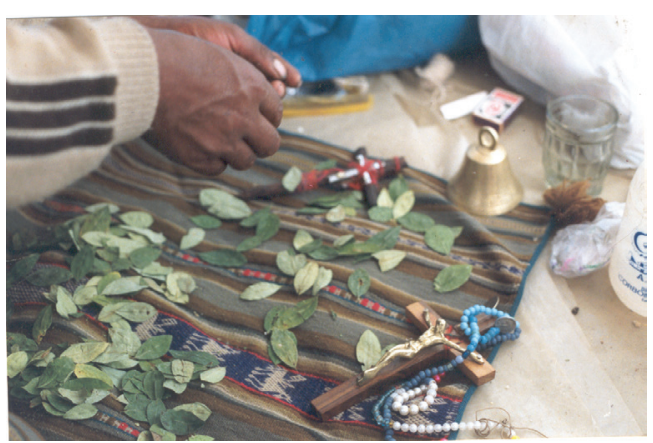

Figura 4: «Calvarios» de Modesto Capcha. Consultando a las hojas de coca.

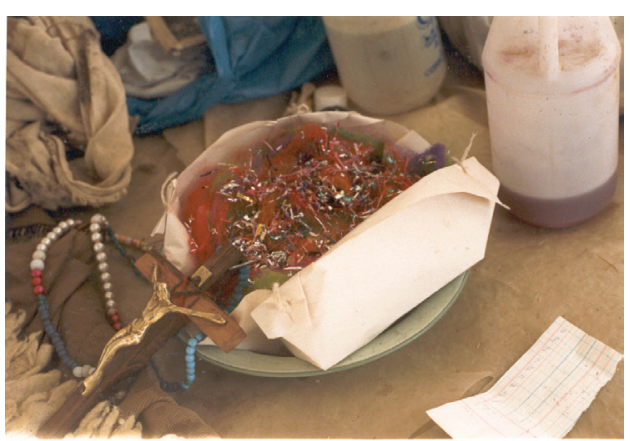

Figura 5: Mesa de «color» destinada a pachama$m a$ en agosto. En primer término, «calvario» de Modesto Capcha.

Emplea Modesto un «calvario» secundario algo más pequeño que el principal, que suele utilizar colgado del cuello, introducido en el tari de hojas de coca para las consultas que le hacen sus clientes. Al abrir el tari y ver la disposición de las hojas se aprecia la presencia de este "calvario», caracterizado por la superposición de un pequeño crucifijo plateado sobre el principal de madera, unidos con el mismo kayitu o lana de colores que se emplea en la elaboración de las ofrendas rituales. De hecho, este tipo de lana de colores se suele colocar en diferentes objetos ceremoniales (como las illas, los talismanes de propiciación del ganado, amuletos, fetos) con la intención de que adquieran vivacidad desde una perspectiva simbólica. De esta forma se asegura a través del color adherido al «calvario» el poder necesario para agudizar el diagnóstico o consulta de la hoja de coca. Las técnicas de diagnóstico y augurio a través de la consulta a la hoja de coca, discrimina las características de las figuras que forman las hojas al lanzarse con la mano derecha sobre el tari, el tejido ceremonial donde se han colocado varias de ellas seleccionadas previamente. El brillo, la ductilidad, la forma de la hoja, sus acumulaciones sobre el tejido ritual, constituyen parte del criterio de interpretación, así como la prevalencia del haz o del envés de las hojas que representan las admoniciones o las solicitudes del especialista ritual al deslizarlas sobre aquellas otras hojas que encarnan a los devotos o clientes (Carter y Mamani 1986; Nava 2006; Ossio 1989). Una forma muy habitual presente en las consultas de coca es el empleo de dos hojas de coca colocadas en forma de cruz en la cabecera del tari para así comprometer bajo juramento a la coca a decir la verdad ${ }^{36}$

Por lo que respecta a la elaboración de las ofrendas rituales, los «calvarios» cobran especial protagonismo no sólo en la incorporación adecuada de los ingredientes en el plato ritual, sino en las ch'allas y en las recomendaciones que el especialista hace a su clientela, pasándole el crucifijo y la mesa ritual por todo su cuerpo antes de ser quemada (Figura 5).

Los q'uchus o himnos religiosos adaptados a la celebración de la mesa ritual en el ámbito urbano, también requieren la exhibición pública del «calvario» sobre el pecho

36 Los políticos bolivianos del Ejecutivo, antes del advenimiento del gobierno de Evo Morales, solían jurar su cargo con la mano derecha en cruz. 
del oficiante en una actitud acústica y corpórea que pareciera derivada de los propios sacerdotes católicos. Este receptáculo cristiano de inmenso poder ceremonial en toda la cristiandad como es la cruz, aloja en su humilde estructura de madera a uno de los signos ceremoniales representativos del conocimiento ritual en los pueblos andinos, como es el poder del rayo.

Tanto la consulta de la hoja de coca como la elaboración de las ofrendas rituales precisan de la actuación especializada del yatiri, y por tanto, en el caso de los yatiris de Faro Murillo, la exhibición pública de sus «calvarios». Sin embargo, no he apreciado el uso de estos crucifijos más allá del propio «calvario» de Copacabana y de las grandes festividades de Alasitas y Urkupiña. Ni he apreciado este tipo de objeto ceremonial entre los yatiris y ch'amakanis que residen y realizan sus actividades ceremoniales en las comunidades rurales del altiplano lacustre del Titicaca. En estos casos la presencia del rayo está significativamente expuesta en sus propios cuerpos a través de las marcas que acreditan la selección de que han sido objeto por parte del rayo, y no precisan exhibirse o materializarse en ningún tipo de objeto, excepción hecha de las llamadas «piedras del rayo» que, en forma de piedras talladas, certifican junto con las marcas corporales la circunstancia de la elección ceremonial que ha sufrido el candidato a yatiri al ser «golpeado» por el rayo.

Los yatiris de Faro Murillo conocen y también exhiben sus propias marcas, recordemos el caso de Gregorio como ispa reconocido, o bien Gabriel y Modesto, que igualmente muestran marcas alusivas al rayo. Da la sensación de que es la ciudad, con sus necesidades extremas de espectáculo y competencia en clara alusión a las necesidades del pulso urbano, la que hace de los «calvarios de poder» el receptáculo público de las competencias ceremoniales de sus propietarios.

La demanda social que sufren los yatiris en momentos específicos del año, como la víspera del $1^{\circ}$ de Agosto o las grandes celebraciones urbanas a las que me he referido, hace que confluyan en ciertos lugares varios de ellos con sus clientelas correspondientes, estableciendo entonces una implícita competencia ritual en sus correspondientes parafernalias. Portar un «calvario de poder», con «seis rayos» incorporados mediante las cruces que acreditan su elección ${ }^{37}$, supone indudablemente una exhibición explícita del poder ceremonial del maestro que lo porta, en este caso Gregorio, importante para la ampliación de la cartera de clientes de la que vive el yatiri en la ciudad.

\section{Conclusiones}

Los yatiris del sector de Faro Murillo en el Alto de La Paz exhiben unos grandes crucifijos como signo del poder ceremonial que atesoran; reciben la denominación de «calvario» por cuanto encarnan en sí mismos el acontecimiento de selección ceremonial otorgado al rayo en el altiplano aymara. Así como los «calvarios» actúan como marcadores ceremoniales del altiplano, resaltando el lugar donde el rayo ha caído con todo su poder, constituyendo altares que reciben los cuidados y también las precau-

37 Las marcas corporales de los yatiris rurales suelen incluir cicatrices en cabeza y mano, en forma de cruz, como señal de haber sido «golpeados por el rayo». 
ciones de los seres humanos por la condensación en ese espacio del poder ceremonial del rayo, los crucifijos o «calvarios» personales de los yatiris de Faro Murillo exponen de manera pública y sensible, a través de todos los aditamentos que incluyen en su formato externo, convenientemente personalizado por su propietario, el poder del rayo. A mayor número de cruces y crucifijos engastados en la cruz principal, «más rayo», y en consecuencia mayor prestigio como especialista ritual. Obviamente lo que «dice» el crucifijo a través de su atrezo peculiar tiene que estar en consonancia con la biografía ritual de su portador; biografía conocida por sus clientes y respaldada de forma no verbal por el crucifijo que porta, como sucede en el caso de Gregorio: ispa, discapacidad física importante por una caída sufrida de niño, conocedor desde niño de himnos y oraciones católicas, ayudante del cura, caída del rayo, y como yatiri, asiduo visitante de santuarios como el de Copacabana, Quillacollo, apachitas como la de la «cumbre», waraq'apachita, y «calvarios» en cerros de especialización ceremonial como los de Tata Bombori ${ }^{38}$, Pachjiri, Guaqi, etc. (Véricourt 1999). Sólo está acreditada biografía con acontecimientos vitales tan significativos vinculados a la actuación de rayo, y su cuidado compromiso con las visitas a los principales centros ceremoniales del espacio altiplánico aymara, posibilitan la posesión de un «calvario» de poder tan significativo y especial, tan «recargado» de rayo como el de Gregorio.

Siendo el cuerpo del yatiri el lugar específico en el que tradicionalmente el rayo acreditaba la selección del candidato mediante gruesas cicatrices en forma de cruz, o mediante el legado de las llamadas «piedras del rayo» o «gloria balas», los yatiris de Faro Murillo y otros sectores suburbanos han diseñado, a imitación del poder del «tata cura», un modelo de exposición del poder del rayo que utilizan de forma portátil mediante los crucifijos que portan en sus actividades ceremoniales. Los diferentes abalorios incluidos en el crucifijo muestran de forma no verbal las competencias y habilidades del yatiri en sus complejos y sinuosos recorridos por los lindes del mundo altiplánico en sus tres ámbitos específicos: alaxpacha, akapacha y manqhapacha.

Sirvan estos «calvarios» de poder como ejemplo de la importancia atribuida al ámbito competitivo del mercado ceremonial que el mundo aymara construye en los centros urbanos y en los contextos de convergencia sobre los principales espacios ceremoniales. Y de la significativa importancia que adquiere en ellos la puesta en escena, así como del atractivo que los signos aparentes de los motivos del «cielo» y los relacionados con el «catolicismo popular» tienen para el análisis etnográfico y antropológico de las creencias y rituales de las poblaciones andinas contemporánea

\section{Referencias bibliográficas}

AbSI, Pascale

2005 Los ministros del diablo. El trabajo y sus representaciones en las minas de Potosí. La Paz: IRD - IFEA.

38 El santuario de Bombori, en las alturas potosinas, es especialmente competente en la formación de especialistas rituales (Véricourt 1999). En las orillas del lago Titicaca destacan los cerros Pachjiri y Jipi como «formadores» de yatiris, igualmente visitados por Gregorio. 
Albó, Xavier

1979 Achacachi. Medio siglo de luchas campesinas. La Paz: CIPCA.

1995 Bolivia Plurilingüe. Guia para planificadores y educadores. (Tres volúmenes y mapas). La Paz: UNICEF - CIPCA.

1997 «Entrecruzamientos lingüísticos en los rituales qullas». Anuario 1997: 326-353.

2005 «Los nuevos q'uchus católicos aymaras». Revista Volveré 1: 1-16.

Albó, Xavier y Josep BARNADAS

1985 La cara campesina de nuestra Historia. La Paz: UNITAS.

Albó, Xavier, Tomás Greaves y Godofredo SANDoval

1981 Chukiyawu. La cara aymara de La Paz.1 El Paso a la ciudad, Cuadernos de Investigación CIPCA, 21, La Paz: CIPCA.

Arriaga, Pablo Joseph de

1968 «La extirpación de la idolatría en el Pirú» [1621]. Crónicas peruanas de interés indígena. Biblioteca de Autores Españoles. Madrid: Atlas.

BERG, Hans Van den

1989 La tierra no da así no más. Los ritos agrícolas en la religión de los aymaracristianos. Ámsterdam: CEDLA.

CARTER, William y Mauricio MAMANI

1986 Coca en Bolivia. La Paz: Juventud.

CERECEDA, Verónica

1987 «Aproximaciones a una estética andina: de la belleza, al tinku», en Tres reflexiones sobre el pensamiento andino, Thérèse Bouysse.-Cassagne, Olivia Harris y Verónica Cereceda, pp. 133-231. La Paz: Hisbol.

2006 «Mito e imágenes andinas del infierno», en Mitologías amerindias, Alejandro Ortiz, ed., pp. 313-359. Madrid: Trotta.

2011 «Demonios, Barroco y diseños textiles», en Entre cielos e infiernos. Memoria del V Encuentro Internacional sobre Barroco, Norma Campos dir., pp. 259-270. La Paz - Pamplona: Fundación Visión Cultural - Universidad de Navarra.

Cervantes, Fernando

1996 El diablo en el Nuevo Mundo. El impacto del diabolismo a través de la colonización de Hispanoamérica. Barcelona: Herder.

Cervantes, Fernando y Andrew RedDen

2013 Angels, Demons and the New World. Cambridge: Cambridge University Press.

Cottle, Patricia y Carmen Beatriz Ruiz

1993 «La violenta vida cotidiana. Vivir en El Alto», en Violencias encubiertas en Bolivia. Coca, vida cotidiana y comunicación, Xavier Albó y Raúl Barrios, coords., pp. 89-150. La Paz: CIPCA.

EsTENSSORO, Juan Carlos

2003 Del paganismo a la santidad. Lima: IFEA - Pontificia Universidad Católica del Perú.

FERNÁNDEZ JuÁREZ, Gerardo

1998a «Religiosidad popular y heterodoxia en los Andes. El caso del «Niño Compadrito». Revista de Dialectología y Tradiciones Populares LIII (1):101-123.

1998b «Iquiqu y Anchanchu. Enanos, demonios y metales en el Altiplano aymara». Journal de la Société des Américanistes 84 (1): 147-166. 
1999 Médicos y yatiris. Salud e interculturalidad en el altiplano aymara. La Paz: OPS/ OMS/Ministerio de Salud y Previsión Social/CIPCA.

2004 Yatiris y ch'makanis del Altiplano aymara. Sueños, testimonios y prácticas ceremoniales. Quito: Abya-Yala.

2010 «La revuelta de las ñatitas. Empoderamiento ritual y ciclo de difuntos en la ciudad de La Paz (Bolivia)». Revista de Dialectología y Tradiciones Populares LXV (1):185-215.

2012 Hechiceros y ministros del diablo. Rituales, prácticas médicas y patrimonio inmaterial en los Andes (suglos XVI-XXI). Quito: Abya-Yala

FERnÁNDEZ JuÁREZ, Gerardo y Xavier Albó Corrons

2008 «Pachjiri. Cerro sagrado del Titicaca». Revista Española de Antropología Americana 38 (1): 239-255.

Foster, George M.

1962 Cultura y conquista. La herencia española en América. México: Universidad Veracruzana.

GARCÉs, Fernando y Walter SÁNCHEZ

2014 «La colección de escrituras ideográficas andinas del Instituto de Investigaciones Antropológicas y Museo de la Universidad Mayor de San Simón (INIAM-UMSS). Una forma de narrar sin letras», en Escritura Andina. Pictografia e ideografía en Cuero y Papel, INIAM-UMSS, pp.13-37. Cochabamba: Universidad Mayor de San Simón.

GISBERT, Teresa,

1980 Iconografia y mitos indigenas en el arte. La Paz: Edit. Gisbert y Cia.

2011 «El cielo y el infierno en el mundo virreinal del sur andino», en Entre cielos e infiernos. Memoria del V Encuentro Internacional sobre Barroco, Norma Campos dir., pp. 35-48. La Paz - Pamplona: Fundación Visión Cultural - Universidad de Navarra.

GonZÁleZ, Jose Luis

1989 El huanca y la cruz. Creatividad y autonomía en la religión popular. Lima: Idea/ Tarea.

MARISCOTTI DE GöRLITZ, Anna María

1978 «Los curi y el rayo». Actes du XLII Congrès International des Américanistes, vol. 4, pp. 365-375. París.

McDannell, Colleen y Berhnard LANG

2001 Historia del cielo. Madrid: Taurus.

Molina, Ramiro y Xavier Albó

2006 Gama étnica y lingüística de la población boliviana. La Paz: Sistema de las Naciones Unidas en Bolivia.

Monast, Jacques Émile

1972 Los indios aimaraes: ¿Evangelizados o solamente bautizados? Buenos Aires: Lohle.

Nava, Raquel

2006 Prácticas y lenguaje ritual de mujeres yatiris aymaras. Tesis de Licenciatura inédita presentada en la Univesidad Mayor de San Andrés. La Paz 
Ossio, Juan, coord.

1989 La coca: tradición, rito, identidad. México: Instituto Indigenista Interamericano.

Paredes Candia, Antonio

1982 Las alacitas. La Paz: Ed. Popular.

Poma de Ayala, Felipe Guaman

1987 Nueva corónica y buen gobierno [1615]. Crónicas de América 29a-c. Madrid: Historia 16.

REDDEN, Andrew

2008 Diabolism in Colonial Peru, 1560-1750. Londres: Pickering \& Chatto.

RosTworowski, María

1986 Estructuras andinas del poder. Ideología religiosa y política. Lima: Instituto de Estudios Peruanos.

Salvador Hernández, Pedro Pablo

2012 «La peregrinación de la Virgen de Urkupiña. Análisis desde la Antropología de la Salud y Enfermedad». Diálogo Andino 39: 23-38.

SANDOVAl, Godofredo y María Fernanda Sostres

1989 La ciudad prometida. Pobladores y organizaciones sociales en El Alto. La Paz: ILDIS.

SHARON, Douglas

1980 El chamán de los cuatro vientos. Madrid: Siglo XXI.

STRÖBELE-GREGOR, Juliana

1989 Indios de piel blanca. Evangelistas fundamentalistas en Chukiyawu. La Paz: HISBOL.

SZEMINSKI, Jan

2010 «Qué sabemos de qillqa en Qulla Suyu?». Estudios Latinoamericanos 30:129186.

TAYLOR, Gerald

1980 «Supay». Amerindia 5: 47-63.

TiconA, Esteban y Xavier AlBó

1997 Jesús de Machaqa: La marka rebelde, 3. La lucha por el poder comunal. La Paz: CEDOIN/CIPCA.

UNITAS

1988 El Alto desde el Alto. La Paz: Unitas.

VÉRICOURT, Virginie de

1999 Rituels et croyances chamaniques dans les Andes boliviennes. París: L'Harmatan. 